\title{
La desheredación en el nuevo Código Civil
}

\section{Augusto Ferrero}

A IGUAL QUE OTROS institutos sucesorios, la desheredación ha merecido un adecuado tratamiento en el nuevo Código Civil peruano. Las diferencias más importantes respecto a la forma cómo ha sido tratado este tema en el ordenamiento recientemente dictado en relación al anterior, son las siguientes:

1.-El Código de 1936 legislaba la desheredación de manera independiente de la indignidad; el Código de 1984 ha imbricado ambos conceptos al permitir al testador aducir las causales de indignidad para apartar al heredero forzoso.

2.- El Código derogado se ocupaba de todas las causales en un solo artículo; el nuevo las norma en tres artículos, segun si se trata de razones aplicables a los descendientes, a los ascendientes o al cónyuge.

3.-Fl Código anterior extendia las causales de desheredación a todas las de divorcio: este no considera a aquéllas que tienen por objeto sólo la separación de los cónyuges.

4.-Fl ordenamiento de 1936 no permitfa desheredaciones modales o parciales; el actual, por el contrario, excluye de la desheredación a los anticipos de legitima, a los legados, a los alimentos que obliga la ley y a otros derechos que corresponden al heredero.

5. - El nuevo Código impide la desheredación a los incapaces menores de edad y a los mayores que se encuentren privados de discermmiento 


\section{CONCEPTO}

La indignidad es una causal de exclusión para suceder, constituyendo una facultad de los coherederos imputarla mediante la acción correspondiente al heredero o legatario que haya cometido un acto vituperable, contemplado en la ley, contra el causante o sus herederos. Esa institución es aplicable tanto a la sucesión intestada como a la testamentaria.

Instituto afin es la desheredaciòn. Propia solamente de la sucesion testamentaria, consiste en la facultad que tiene sólo el testador de separar de la herencia a un heredero forzoso por alguna de las causales senaladas en la ley, que están referidas a actos deshonrosos. La desheredación es una consecuencia directa de la legitima. Cuando ésta no existe, por tener el causante la libre disposición de todos sus bienes, no opera la desheredación. Los herederos no forzosos pueden ser excluidos sin que el testador exprese causa alguna; pues, precisamente, en ese caso tendrá el testador la libre disposición de la totalidad de sus bienes.

Algunos estudiosos son de opinión de que ambos institutos deben fusionarse en un solo régimen legal aduciendo que son iguales. Otros sostienen que deben analizarse separadamente por tratarse de conceptos distintos que tienen una naturaleza común. Nuestro Código derogado los trató completamente separados. El actual, si bien sigue el mismo criterio, trae una innovación muy importante, al señalar en su articulo 669, que el causante puede desheredar por indignidad a su heredero forzoso conforme a las normas de la desheredación; y puede también perdonar al indigno de acuerdo con dichas normas; $y$ en el artículo 747 , perceptúa que el testador puede fundamentar la desheredación en las causales de indig. nidad. Ello significa que la desheredación puede ser invocada alegando las causales que para ella señala la ley; $y$, además, aduciendo las que el Código expresa para la indignidad. La indignidad puede imputarse sólo por las causales que la ley enumera para esta situación taxativamente Como ya hemos explicado al ocuparnos de la indignidad, la razón de esta extensión se encuentra en que pudiendo ser las causales de indignidad invocadas y hacerse efectivas por algunos sucesores, resultaba injusto que el causante, que es precisamente el ofendido por los actos delictuosos o vituperables constitutivos de la indignidad, no pudiera invocarlos para excluir de su herencia al indigna, por no ser causales de desheredación.

Al igual que tratándose de la indignidad, los incapaces menores de edad y los mayores que por cualquier causa se encuentren privados de discernimiento no pueden ser desheredados, por mandato del articulo 
748. La razón se encuentra en que siendo personas incapaces de practicar actos juridicos, deben ser consideradas como irresponsables al incurrif en los actos u omisiones que la ley permite sancionar con la desheredaciōn.

Las diferencias entre la indignidad y la desheredación resultan, asi, las siguientes:

1. - La indignidad se aplica tanto en la sucesión intestada como en la testamentaria: la desheredación funciona sólo cn esta última.

2. - La indignidad puede ser invocada por cualquier coheredero y no por el testador; la desheredación, sólo por éste.

3.- La indignidad es atribuible a cualquier sucesor: heredero o legatario; la desheredación, sólo a los herederos forzosos.

4. - La indignidad se circunscribe a las causales que para ella sethala la ley; la desheredación tiene como causales las que para ella sefala la ley más las de indignidad.

5.-Las causales je indignidad se refieren. en todos los casos, a actos contra el causante o sus herederos; la desheredación se amplía a la conducta deshonrosa $o$ inmoral en general.

6.- La indignidad queda sin efecto mediante el perdón; ta desheredación mediante la revocación.

El artículo 742 señala que por la desheredación el testador puede privar de la legitima al heredero forzoso que hubiera incurrido en alguna de las causales previstas en la ley. La desheredación está tipificada como un castigo. Para que opere, la causal debe ser expresada claramente en el testamento; pues la dispuesta sin expresión de causa, o por causa no señalada en la ley, o sujeta a condición, no es válida; siendo anulable la fundada en causa falsa (artículo 743). Esta nueva disposición es más completa que la que existía en el artículo 714 del Código derogado, el cual expresaba que las desheredaciones modales o parciales se reputaban no hechas. Sin embargo, la expresión "modal" utilizada en el Código anterior es más amplia que la voz "condición", empleada en el actual, como se ha hecho presente reiteradamente; pues comprende además el plazo y el cargo. A su vez, se mantiene la exclusividad del testamento como forma de declarar la desheredación. Es decir, la desheredación no puede hacerse 
por otro documento, ni siquiera por escritura publica, salvo que esta se otorgue cumpliendo las formalidades que establece la ley para esta clase de testamento.

Lanatta expresa, en la Exposición de Motivos, que las causales de desheredación son privativas del causante, porque sólo éste puede compulsarlas debidamente y porque su manejo no puede ser dejado en manos de los coherederos, que podrian utilizarlas maliciosamente si estuvieran dentro del régimen de la indignidad. Explicando la razón por la que se acordó mantener esta institución en el nuevo ordenamiento, recalcó que la crisis por la que atraviesa la familia en el mundo actual no debe ser motivo para suprimir la desheredación; sino, por el contrario, para mantenerla y regularla mús cuidadosamente.

Finalmente, debe distinguirse la diferencia entre la desheredación y la preterición. Esta última implica el olvido o la omisión por el testador de quienes son sus herederos forzosos. produciendo la invalidación de la institución de herederos en cuanto resulte afectada la legitima que corresponde a los preteridos (articulo 806).

\section{CAUSALES DE DESHEREDACION}

Las causales de desheredación deben interpretarse taxativamente; es decir, son de aplicación sólo las que determina la ley como tales, más las de indignidad, como se ha explicado. Este carácter limitativo fue confirmado por ejecutoria suprema del I de junio de 1954.

El Código de 1936 contemplaba todas las causales de desheredación juntas, referidas tanto a los descendientes como a los ascendientes y al cónyuge. El nuevo ordenamiento las trata separadamente en los artículos 744,745 y 746 , de la siguiente manera:

\section{1.-Desheredación de los descendientes.}

a) Haber maltratado de obra o injuriado grave y reiteradamente al ascendiente o a su cónyuge si éste es tambiên ascendiente del ofensor.

Esta causal ha sido rescatada del Código de 1852, que se referia a las injurias graves al causante, y de los Anteproyectos del Código de 1936, que hablaban de injurias que el Código Penal reprimiera como delitos. En el Código derogado no apareció esta causal. 
El enunciado de este inciso se refiere al maltrato fisico cde obra) y al verbal (injuria grave). El adverbio "reiteradamente" debe entenderse en relación a ambos conceptos, y en nuestra opinión acusa una consideración que no debió tener en cuenta el legislador. Debiera bastar un solo maltrato para justificar la causal. Según el Diccionario de la Lengua Espanola, "reiterar" significa volver a decir o ejecutar, repetir una cosa. Quiere decir que deberá probarse que la acción se ha efectuado por lo menos dos veces para que se dé la causal.

La causal no se refiere a los ascendientes en general, los cuales son padre y madre, abuelo y abuela, etc. Se remite al ascendiente de cuya herencia se trata y no a los demás. Por eso incluye al cónyuge de èste, que también debe ser ascendiente del ofensor. Por ejemplo, el maltrato o injuria al abuelo no le da al padre derecho a desheredar al hijo. Tiene que ser el propio ofendido, o cuando lo es el cónyuge de éste, quien deshereda. De lo contrario, la causal se referiria simplemente a los descendientes.

b) Haberle negado el ascendiente, sin motivo justificado, los alimentos o haberlo abandonado encontrándose éste gravemente enfermo o sin poder valerse por sí mismo.

La primera parte de esta causal estaba prevista en el ordenamiento derogado, y se refiere a la obligación legal de los descendientes de prestar alimentos a los ascendientes, que emana del articulo 474 . Lanatta se pregunta si para que se dé esta causal es o no necesario que la negativa de prestar los alimentos conste en juicio, a lo que responde que no en su opinión, criterio con el que concordamos. Bastará que en el proceso se pruebe que hubo negación a prestar alimentos. Echecopar coincide con esta opinión; expresando, además. que la mayoría de los tratadistas están de acuerdo en que si el solicitante de los alimentos no los necesitaba no habría lugar a la desheredación.

La segunda parte de la causal se remite a una obligación moral respecto de los casos de alienación mental o de grave enfermedad del ascendiente, como nos informa Lanatta en la Exposición de Motivos.

Esta causil resulta en los hechos de dificil aplicación, pues para que opere se requicre que el ascendiente tenga una situación económica precaria que lo haga necesitar de alimentos, en cuyo caso no tendrá patrimonio que dejar a sus herederos. Asi. la desheredación resultara poco efectiva 
mente.

c) Haber privado de sa libertad al ascendiente injustificada-

Esta causal no estaba en el Código de 1936, mas si en el de 1852. En el Anteproyecto Lanatta y en los dos Proyectos no figuraba el adverbio "injustificadamente", el cual apareció al publicarse el Código Civil. Intuimos que la inclusión de esta voz obedece a que, en algunos casos, se produce una privación de la libertad en beneficio del ascendiente afectado; quien, por pérdida de facultades mentales, aunque sea momentánea, puede ser protegido por la familia recortando su libertad de movimiento.

d) Llevar el descendiente una vida deshonrosa o inmoral.

La causal de prostitución, a que se referia el Código derogado, se ha ampliado por una más extensa referida a la conducta deshonrosa $o$ inmoral en general.

\section{2,-Desheredación de los ascendientes}

a) Haber negado éstos injustificadamente los alimentos a sus descendientes.

Como la obligación de prestarse alimentos entre ascendientes y descendientes es recirpoca (artículo 474 ), esta causal contempla la misma situación analizada a la inversa.

b) Haber incurrido el ascendiente en alguna de las causales por las que se pierde la patria potestad, o haber sido privado de ella.

De acuerdo al artículo 462 , la patria potestad se pierde por condena a pena que la produzca o por abandonar al hijo durante seis meses continuos o cuando la duración sumada del abandono exceda de este plazo.

La privación de la patria potestad, conforme al artículo 463 . procede en los siguientes casos:

1. Por dar órdenes, consejos, ejemplos corruptos o dedicar a la mendicidad a sus hijos.

2. Por tratarlos con dureza excesiva.

3. Por negarse a prestarles alimentos. 
Obsérvese que el inciso no sanciona sólo al que pierde o es privado de la patria potestad en virtud de una resolución judicial, sino que basta que se pruebe que se incurrió en alguna de las causales para tllo.

\section{3.-Desheredación del cönyuge}

Son causales de desheredación del cónyuge las previstas en el artículo 333 , incisos 1 a 6 , que son:
a. El adulterio.
b. La sevicia.
c. El atentado contra la vida del cónyuge.
d. La injuria grave.
e. El abandono injustificado de la casa conyugal por más de dos años continuos o cuando la duración sumada de los períodos de abandono exceda a este plazo.

f. La conducta deshonrosa que haga insoportable la vida en común.

El Código anterior extend áa las causales de desheredación á todas las de divorcio, lo cual era excesivo. Lanatta las redujo a cuatro, y la Comisión Revisora incluyó dos más: el atentado contra la vida del cónyuge o el abandono injustificado del hogar conyugal citado. La primera era innecesaria, pues existe de por sí como primera causal de indignidad (artículo 667, inciso 1), pudiendo el testador fundamentar en ella la desheredación (artículo 474). La segunda sí nos parece pertinente, porque revela una conducta que hace justificable la desheredación. Bien dijo Lanatta que las otras causales de divorcio tienen por objeto la separación de los cónyuges o la ruptura del vinculo matrimonial y, como efecto de ésta, la pérdida de la herencia; pero no son apropiadas para configurar causales de desheredación.

Es evidente que para que se produzca la causal no es necesario que se haya declarado el divorcio, pues éste acaba con la condición de heredero forzoso del cónyuge. Asi, el artículo 353 declara que los cónyuges divorciados no tienen derecho a heredar entre si.

\section{PARCIALIDAD DE LA DESHEREDACION}

El artículo 714 del Código derogado establecía que las desheredaciones modales o parciales se reputaban no hechas. Estando la desheredación referida a la legitima, el enunciado podia interpretarse respecto a 
ésta. a la herencia en general o a todo el patrimonio dejado por el causante, incluyendo los legados. Lanatta lue de esta última opinion y. para eliminar la severidad de la norna, consagró el nuevo articulo 749 , que proclama que "los efectos de la desheredación se refieren a la legitima y no se extienden a las donaciones y legados otorgados al hefedero, que el causante puede revocar, ni a los alimentos debidos por ky, ni a otros derechos que corresponden al heredero con motivo de la muerte del testador".

De esa manera, quien deshereda priva al heredero forzoso de su legítima y de su cuota hereditaria en la medida que no haya dispuesto de la porción de libre disposición. La desheredación no se extiende a los siguientes conceptos:

1.-Las donaciones, o sea, los anticipos de legítima, si no lo declara expresamente el testador. lo cual esti facultado a hacer: pues, conforme al articulo 1637, el donante puede revocar la donación por las mismas causas de indignidad para suceder y de desheredación.

2.- Los legados, pues éstos con mayor razón pueden ser revocados en cualquier momento sin expresión de causa, porque son con cargo a la porción disponible y tienen efecto sólo con la muerte del causante.

3.- Los alimentos a que obliga la ley, según el artículo citado. En la Exposición de Motivos al mismo, el ponente critica que la desheredación se extienda al derecho a alimentos, calificando ello de excesiva rigurosidad. No obstante, notamos aquí cierta descoordinación entre los legisladores; pues los alimentos debidos por ley, de acuerdo a la definición expresada en el articulo 472 , deben ser lo indispensable para el sustento, habitación, vestido y asistencia médica, según la situación y posibilidades de la familia; incluyendo educación, instrucción y capacitación para el trabajo cuando el alimentista es menor de edad. Pero el artículo 485, repitiendo el tenor del artículo 452 del Código derogado, expresa que "cl alimentista que sea indigno de suceder, o que pueda ser desheredado por el deudo de los alimentos, no puede exigir sino lo estrictamente necesario para subsistir" Este minimo de subsistencia es definitivamente menor que la obligación alimenticia en general descrita en el artículo 472 citado. Por lo tanto, la desheredación si restringe los alimentos al minimo de subsistencia.

4 Otros derechos que corresponden al heredero. El legislador. como to explica en la Exposición de Motivos, consagra en este enunciado lo expuesto por la resolución suprema de 8 de julio de 1954, que declaró 
que el desheredado no pierde el derecho de representar al causante en otra herencia.

\section{ACCIONES PROCESALES}

Tres artículos del Código se ocupan del derecho del desheredado o de sus sucesores de contradecir la desheredación, del derecho del testador de promover juicio para justificarla, $y$ del derecho $y$ deber de los herederos de representar a su causante cuando se inicia una acción de contradicción. Los procesos son dos:

\section{1.-Acción de contradicción}

El articulo 750 señala que el derecho de contradecir la desheredación corresponde al desheredado o a sus sucesores, $y$ se extingue a los dos años contados desde la muerte del testador, o desde que el desheredado tiene conocimiento del testamento.

La segunda parte del enunciado, referida al cómputo del plazo desde que el desheredado conoce su situación, es una novedad que no estaba contemplada en el antiguo Código. Es muy justa; pues, por tratarse de un plazo de caducidad, resultaba inicuo que se tomara en cuenta sólo desde la muerte deI causante. Aunque el Código no lo dice, es obvio que el inicio del plazo es con la apertura de la sucesión, es decir, desde el momento de la muerte del causante. El hecho de que no proceda en vida del causante ha sido objeto de crítica por algunos; pues se impide al desheredado dar explicaciones al causante, quien pudiera haber sido presa de intrigas o rencores.

El articulo 752 manifiesta que en caso de no haberse promovido juicio por el testador para justificar la desheredación, corresponde a sus herederos probar la causa si el desheredado o sus sucesores la contradicen Esta norma es nueva en nuestro ordenamiento y resulta atinada; pues. procesalmente, la regla general es que la carga de la prueba se le atribuye al demandante (art ículo 338 del Código de Procedimientos Civiles). Por ello, era necesario en este caso norma expresa que trasladase dicha cargat al demandado, quien deberá probar la causa; lo cual resulta más congruente que obligar al demandante a probar la inexistencia de causa, EI Código anterior omitió esta disposición a pesar de aparecer en los Anteproyectos respectivos, con lo que se entendia que correspondia al des. heredado prohar la injusticia de la desheredación. 
Quiere decir oue el desheredado actua como demandante v los herederos deben ser citados a juicio como demandados, correspondiéndoles probar la causa.

\section{2.-Acción de desheredaciön}

El mismo testador, de acuerdo a lo dispuesto en el articulo 751 . puede promover juicio para justificar su decisión de desheredar. Esta acción es facultativa. Si es amparada en la sentencia, ésta no puede ser contradicha.

\section{EFECTOS}

La desheredación produce en el desheredado el apartamiento forzoso de la herencia. Esto tiene varios efectos. El primero de ellos ha sido analizado por las consecuencias procesales que produce.

El desheredado que entra en posesión de la herencia es un heredero aparente, pudiendo los herederos no sólo defenderse en el proceso que éste inicie contradiciendo la desheredación sino, además, incoar la acción de petición de herencia; salvo que el desheredado contradiga la desheredación y obtenga éxito en el juicio.

Otro efecto, relacionado con la representación sucesoria, es el carácter personal de la desheredación. Antiguamente, se criticó este instituto precisamente por el perjuicio que causaba a la estirpe del desheredado Por ello, se legisló para que sus efectos se extingan con el autor de la causal y no se extiendan a sus herederos. Así lo determina el artículo 681 . al expresar que los descendientes del desheredado tienen derecho de entrar en su lugar y en su grado a recibir la herencia que a aquél le hubiese correspondido de no haberla perdido, y el artículo 755 , al señalar que los descendientes del desheredado heredan por representación legítima que correspondería a éste si no hubiere sido excluido. Esta representación opera en la línea recta de los descendientes sin limitación alguna. Respecto a la línea colateral, pensamos que no, a pesar que el artículo 685 expresa que en ésta se aplica siempre que el testador no indique lo contrario. En realidad, la norma es aplicable a los otros tres casos en que opera la representación: premoriencia, renuncia e indignidad. No así a la desheredación, pues este instituto no funciona tratándose de la línea colateral, por cuanto quienes pertenecen a ésta no son herederos forzosos. En consecuencia, pueden ser apartados de la herencia sin necesidad 
de aducir razón alguna. Es más, las causales de desheredación se refieren a los descendientes, a los ascendientes y al cónyuge. No existen, como es lógico, causales de desheredación para los parientes colaterales. Por ello, creemos que la desheredación a un hermano afecta a toda su estirpe. no actuando la representación; salvo que el testador la disponga, con lo cual se trataria de una institución de herederos y no de una sucesión por representación. Al no haber representación se produce la acreencia en favor de los demás herederos. Al ser la desheredación una figura ajena a la línea colateral, de dictarla el testador debería interpretarse que su intención ha sido la de separar al hermano y a los descendientes de éste, lo cual estả permitido hacer por no ser los hermanos herederos forzosos. Quiere decir que, para apartarlos de la herencia, no se necesita siquiera expresión de causa. En consecuencia, su separación expresa o tácita queda fuera de los alcances del instituto de la desheredación, y no beneficia a sus descendientes. Por ello, el articulo 755 citado se refiere a quienes heredan por representación "la legítima"; quienes no pueden ser otros que los descendientes.

Congruente con lo expuesto, el desheredado está exceptuado del usufructo legal de la herencia que ha pasado a sus hijos por desheredación. según manda el artículo 436 , inciso 3 , concordante con el artículo 755 : el cual agrega que tampoco tendrá derecho a la administración de los bienes. De esa forma, se le priva al desheredado de una de las atribuciones de la patria potestad, cual es la de hacer sayos los frutos de los bienes de los hijos menores de edad.

\section{REVOCACION}

El artículo 753 expresa que la desheredación queda revocada por instituir heredero al desheredado o por declaración expresada en el tesiamento o en escritura pública; agregando que, en tal caso, no produce efecto el juicio anterior seguido para justificar la desheredación.

La revocación, al igual que el perdón en el caso de la indignidad, produce el olvido toial de la causa que originó la desheredación, dejándola para siempre sin efecto. Sólo podrá renovarse por un hecho nuevo que la justifique.

Resulta interesante obscrvar cómo a pesar de que la desheredación puede ser hecha sólo por testamento, la ley permite que sea revocada por escritura pública. Esta solución contraviene en cierta forma el principio 
expresado en el artículo 799 , en el sentido que la rovocación expresa del testamento, total o parcial, o de algunas de sus disposiciones. sólo puede ser hecha por otro testamento, cualquiera que sea su forma. La excepción a la regla se explica por la necesidad de facilitarle al testador el perdón.

\section{RENOVACION}

El artículo 754 agrega que revocada la desheredación no puede ser renovada sino por hechos posteriores.

Echecopar decia, con razón, que se comprende el sentido de esta disposición porque no es posible tolerar cambios en decisiones tan graves, ni que se rovoque la desheredación y se renueve basindose siempre en las mismas razones. 